\title{
Soil/litter beetle abundance and diversity along a land use gradient in tropical Africa (Oumé, Ivory Coast)
}

\author{
KraD. KouAdio ${ }^{1 *}$, Mamadou DoumBIA ${ }^{1}$, Klimaszewski JAN², Mamadou DaGnOGO ${ }^{1}$ \& DaoudaAIDARA ${ }^{1}$ \\ ${ }^{1}$ UFR/SN, Biology Laboratory and Animal Cytology, University Abobo-Adjamé, 02 BP 801 Abidjan 02, Ivory Coast. ; phone: (+225) \\ 070463 69/02 5537 61; 14 BP 600, Abidjan) \\ ${ }^{2}$ Natural Resources Canada, Canadian Forest Service, Laurentian Forestry Centre, 1055 du PEPS, PO Box 10380, Stn. Sainte- \\ Foy, Quebec, QC, Canada G1V 4C7 \\ *Corresponding author (E-mail: luckaskra@yahoo.fr) \\ Received 16-09-2008, accepted 08-05-2009.
}

\begin{abstract}
Beetles represent a component of arthropods that contributes to enrichment and circulation of mineral elements retained in litter and the topsoil. We have studied beetle abundance, diversity, and distribution in response to anthropogenic activities (farming, urbanization, etc.). Two collecting methods were used: soil monoliths extraction, and sifting and processing of soil and litter samples in a mini-winkler extractor. This study was conducted in the central-western part of Ivory Coast, near Oumé in eight agroecosystems with five types of habitats. Our results showed that secondary forests had the highest beetle abundance, but the highest diversity was found in the fallows. The families represented in the majority of agroecosystems are Staphylinidae, Scydmaenidae, Curculionidae, Pselaphidae, Scarabaeidae and Carabidae. The regenerating forest plantations and cocoa plantations were characterized by lower beetle abundance and diversity. The study demonstrated that beetle abundance and diversity were affected by human activities and depended on the intensity of land use.
\end{abstract}

Keywords: Beetle, abundance, diversity, agroecosystems, anthropogenic activities

\section{Résumé}

Abondance et diversité des Coléoptères du sol et de la litière le long d'un gradient d'utilisation des terres en Afrique tropicale (Oumé, Côte d'Ivoire).

Les Coléoptères sont une composante des arthropodes qui participent à l'enrichissement et à la circulation des éléments minéraux de la litière et du sol. L'abondance et la diversité des Coléoptères ont donc fait l'objet d'une étude pour voir l'impact des activités anthropogéniques (agriculture, urbanisation, etc.). Deux méthodes de collecte ont été utilisées : extraction à partir des monolithes du sol, et extraction des Coléoptères à partir des winklers après tamisage des échantillons de sol et de litière. Les travaux se sont déroulés dans le centre ouest de la Côte d'Ivoire, près de Oumé dans 8 agroécosystèmes formant cinq types d'habitat. II ressort des résultats que les forêts secondaires ont l'abondance la plus élevée mais, la diversité la plus élevée est trouvée en jachères. Les familles présentes dans la majorité des agroécosystèmes sont les Staphylinidae, Scydmaenidae, Curculionidae, Pselaphidae, Scarabaeidae et les Carabidae. Les agroécosystèmes reboisés et les cacaoyères sont caractérisés par les plus faibles abondances et diversités. Ces travaux ont montré que l'abondance et la diversité des Coléoptères du sol sont affectées par les activités humaines et cela dépendent de l'intensité d'utilisation du sol. Mot clés : Coléoptères, abondance, diversité, agroécosystèmes, activités anthropogéniques. 


\section{Introduction}

Soil arthropods consist of a large number of species (Giller, 1996). They play an important role in many functions such as mineral element recycling and soil structure dynamics (Setälä et al., 1998; Wall \& Moore, 1999; Barros et al., 2004). Soil management can have dramatic effects on soil invertebrate communities (Beare et al., 1997; Fragoso et al. 1997; Giller et al., 1997; Barros et al., 2002, 2003; Decaëns et al., 2004), and may therefore lead to important changes in soil structure and functioning. Beetles are well represented in all terrestrial habitats by many species, genera, and families, which are often used as indicators of environmental change because of their great habitat specificity (Forsythe, 1987; Lövei \& Sunderland, 1996). Many beetle life cycles are associated with soil and ground litter and are affected by environmental changes caused by various human activities (agriculture, urbanization, etc.). Many studies have paid attention to the response of beetles to habitat heterogeneity induced by human activities (Thomas, 1983; Magagula, 2003; Krell et al., 2005; Lassau et al., 2005; Kra et al., 2008). However, little attention has been paid to the response of soil/litter beetles to human activities in the forests of tropical Africa particularly in Ivory Coast. The use of this group depends on knowledge of their distribution in space and time. The urgent need to develop an understanding of sustainable forestry and agricultural practices in tropical countries were the main reasons for undertaking the present study. The objective of this study is to evaluate the impact of human activities on beetle abundance and diversity along a gradient of land use.

\section{Materials and Methods}

\subsection{Study site}

The study site was located in the central-western part of Ivory Coast, near Oumé, $6^{\circ} 30^{\prime} \mathrm{N}, 5^{\circ} 31^{\prime} \mathrm{W}$. The site was chosen because it has traditional cocoa plantations and it is presently undergoing an intense land transformation to agriculture with remnants of intact relict wet forests. The study site includes various types of agroecosystems, and a protected zone containing patches of undisturbed forest and regenerating forests of various ages. This area is managed by the State Forest Agency (SODEFOR). The experimental fields were included in a grid system, which comprised 107 sampling points, each separated from it's neighbour by a distance of $200 \mathrm{~m}$. The sampling was conducted in the most representative land-use type of the study site: primary forest (PF), secondary forest (SF), multispecies plantation (MP), 10 and 4-year-old teak plantations (TK10 and TK4), cocoa plantations (CC), fallows or rural fallows (FA) and mixedcrop field (MC). The forest consisted of primary forest and secondary forest. The vegetation canopy of the primary forest was fully closed and undergrowth was represented by some lianas, dead wood, and many species of Caesalpiniaceae, Marantaceae, and Moraceae. The secondary forest underwent a forest fire in 1983, the canopy was closed, and the undergrowth consisted of many lianas, dead wood, and shrubs. The multi-species plantations, 10-year-old teak, and 4-year-old teak, represented three types of forest plantations. The canopy of the 10-year-old teak was dense and that of the 4-year-old teak was sparse. The multispecies plantation was planted with local and exotic species of Combretaceae, Meliaceae, and Verbenaceae.

The most important species in the cocoa plantations were Theobroma cacao L. (Sterculiaceae), and other species belonging to the Arecaceae, Poaceae, and Mimosaceae. In the mixed-crop field, vegetation was dominated by species of Meliaceae, Sterculiaceae, Solanaceae, and Poaceae. The rural fallows consisted of regenerating bush and low vegetation and was dominated by species from the Apocynaceae and Periplocaceae families.

\subsection{Sampling design}

Beetle collection protocol was conducted within the framework of a multidisciplinary project Conservation and Sustainable Management of Below-Ground Biodiversity (CSM-BGBD). The Ants of Leaf Litter protocol (ALL) or protocol for litter ants and the soil monoliths extraction were used to collect Coleoptera. Two 50-m transects, set $10 \mathrm{~m}$ apart, were established in each sampling area, one for litter sampling and one for soil monoliths. 
The first transect was established according to a modified ALL (Ant Leaf Litters) protocol (Agosti \& Alonso, 2000), based on sifting litter and processing it through a mini-winkler extractor. It included 5 litter samples, each collected from 1 $\mathrm{m}^{2}$ and located $10 \mathrm{~m}$ apart. Each sample was collected during 5 minute periods by two people. The litter collected in the field was later processed through a mini-winkler extractor in the laboratory. Litter sampling and placing of the sifted material in the mini-winkler extractor was undertaken in the morning of the collecting day at each new site. The samples were removed from the mini-winkler extractor in the afternoon of the third processing day. This ensured that all sieved material was in the mini-winkler extractor for 48 hours. This method provided samples of beetle species occurring in litter but not in the soil. Additional transects were established 10 $\mathrm{m}$ apart from the litter transect to include the soil beetle species. We dug out soil cubes $(30 \times 30 \times$ $30-\mathrm{cm}$ ) and searched for individual beetles. Beetles were preserved in $80 \%$ ethanol. The identification keys and illustrations of Delvare and Aberlenc (1989), Lawrence et al. (1999), and Leraut (2003) were used.

\subsection{Data processing and statistical analyses}

Shannon and Shannon-Weiner indexes were used to evaluate the biodiversity richness and evenness indexes. The interrelationship of this index with the sampling size provides the best evaluation of the population diversity from a given sample. The Shannon-Wiener index is defined by comparing the Shannon index with a hypothetical Shannon index that would correspond to a maximal diversity, i.e., that in a real population where all species have the same coefficient. Observed and estimated family were computed using EstimateS version 7.5 (Colwell, 2005). The Ecological methodology (Krebs, 2002), version 6.1 was used to estimate Shannon-Wiener index. Evenness indexes in each habitat were calculated by scaling the Shannon index of diversity to its maximum value. For the groups of beetles examined, differences between their abundance mean values were tested using the Kruskal-Wallis test. Comparisons of beetle abundance and diversity between the different agroecosystems were carried out using the LSD test following verification of the homogeneity of variances with Levene's test. These statistical analyses were processed using the STATISTICA ver. 6.0 software programme (STATISTICA, Tulsa, OK). All results were significant when $p<0.05$. To better visualize the similarities at habitat level, a cluster analysis package in STATISTICA was used. The matrix of dissimilarity was constructed with the complementary values between agroecosystems (1- Sorensen index of similarity) and UPGMA (Unweighted Pair-Group Method using arithmetic Averages) was used as the clustering method.

For easier presentation, beetle families were classified into three groups on the basis of the number of individuals for each family as abundant, common, rare: abundant ( $\mathrm{z} \geq 100)$, common $(10 \leq n<100)$, and rare $(n<10)(n=$ number of specimens).

\section{Results}

\subsection{Beetle abundance}

32 families of beetles identified were grouped as follows: abundant (3 families), common (12 families), and rare (17 families) (Table 1). The abundant beetle group (Staphylinidae, Scydmaenidae, and Curculionidae) was well represented in the secondary forest. The common beetle group was well represented in the primary forests, secondary forests, and mixed-crop fields. In this group, the three dominant families were Pselaphidae, Scarabaeidae, and Carabidae. The test did not reveal significant variation of abundance in the abundant group $(p=0.1006)$ and common beetle group $(p=0.273)$ in different ecosystems, but the rare beetle group varied significantly $(p=0.0029)$. Indeed, more individuals were collected in the secondary forest ( 244 individuals, on average 61/site) than in the 4-year-old teak plantation (39 individuals, on average $9.75 /$ site). The variation in average beetle abundance in all habitats was highly significant $(p=0.001)$. Beetle abundance in secondary forest differed from that of the other habitats, except for those of the fallows and primary forests (Fig. 1). 
Table 1: Distribution of beetles in agroecosystems, PF (primary forest), SF (secondary forest), MP (multi-species plantation), TK10 (10-year-old teak), TK4 (4-year-old teak), CC (cocoa plantation), FA (rural fallow), MC (mixed-crop field)

\begin{tabular}{lccccccccc}
\hline Family & PF & SF & MP & TK10 & TK4 & CC & FA & MC & Group of beetles \\
\hline Staphylinidae & 70 & 94 & 35 & 40 & 19 & 25 & 43 & 38 & \\
Scydmaenidae & 37 & 55 & 15 & 16 & 2 & 3 & 42 & 15 & Abundant group \\
Curculionidae & 17 & 33 & 23 & 13 & 0 & 15 & 32 & 2 & \\
\hline Pselaphidae & 19 & 13 & 0 & 3 & 3 & 1 & 9 & 8 & \\
Scarabaeidae & 11 & 16 & 6 & 1 & 0 & 1 & 2 & 11 & \\
Carabidae & 7 & 11 & 5 & 11 & 15 & 3 & 29 & 15 & \\
Chrysomelidae & 0 & 3 & 2 & 1 & 0 & 4 & 10 & 6 & \\
Anthicidae & 1 & 1 & 2 & 3 & 0 & 0 & 9 & 12 & \\
Scolytidae & 3 & 4 & 1 & 1 & 0 & 8 & 5 & 2 & Common group \\
Histeridae & 13 & 2 & 0 & 0 & 0 & 2 & 0 & 0 & \\
Mycetophagidae & 0 & 1 & 4 & 0 & 0 & 0 & 9 & 0 & \\
Nitidulidae & 2 & 1 & 0 & 1 & 0 & 4 & 3 & 0 & \\
Silvanidae & 0 & 1 & 3 & 0 & 0 & 0 & 3 & 6 & \\
Erotylidae & 2 & 2 & 0 & 1 & 0 & 1 & 1 & 6 & \\
Cucujidae & 0 & 0 & 0 & 0 & 0 & 0 & 11 & 2 & \\
\hline Agyrtidae & 0 & 0 & 0 & 0 & 0 & 1 & 6 & 0 & \\
Monotomidae & 0 & 0 & 0 & 0 & 0 & 0 & 0 & 4 & \\
Tenebrionidae & 3 & 3 & 0 & 1 & 0 & 0 & 1 & 0 & \\
Cryptophagidae & 0 & 0 & 4 & 0 & 0 & 0 & 0 & 0 & \\
Dermestidae & 1 & 0 & 0 & 0 & 0 & 0 & 0 & 2 & \\
Cleridae & 0 & 2 & 2 & 0 & 0 & 1 & 0 & 2 & \\
Mordellidae & 0 & 1 & 0 & 0 & 0 & 0 & 1 & 1 & \\
Zopheridae & 1 & 0 & 0 & 0 & 0 & 0 & 0 & 0 & Rare group \\
Scaphidiidae & 1 & 0 & 0 & 0 & 0 & 0 & 0 & 0 & \\
Anobiidae & 0 & 0 & 0 & 0 & 0 & 0 & 1 & 0 & \\
Lagriidae & 0 & 0 & 0 & 0 & 0 & 0 & 1 & 0 & \\
Cerambycidae & 0 & 0 & 0 & 0 & 0 & 0 & 1 & 0 & \\
Alleculidae & 0 & 1 & 0 & 0 & 0 & 0 & 0 & 0 & \\
Dytiscidae & 0 & 0 & 1 & 0 & 0 & 0 & 0 & 0 & \\
Byrrhidae & 0 & 0 & 0 & 0 & 0 & 0 & 1 & 0 & \\
Endomychidae & 0 & 0 & 0 & 0 & 0 & 0 & 1 & 0 & \\
Ptinidae & 1 & 0 & 0 & 0 & 0 & 0 & 0 & 0 & \\
Total & 189 & 244 & 103 & 92 & 39 & 69 & 221 & 132 & \multirow{2}{*}{1089} \\
\hline & & & & & & & & & \\
\hline
\end{tabular}

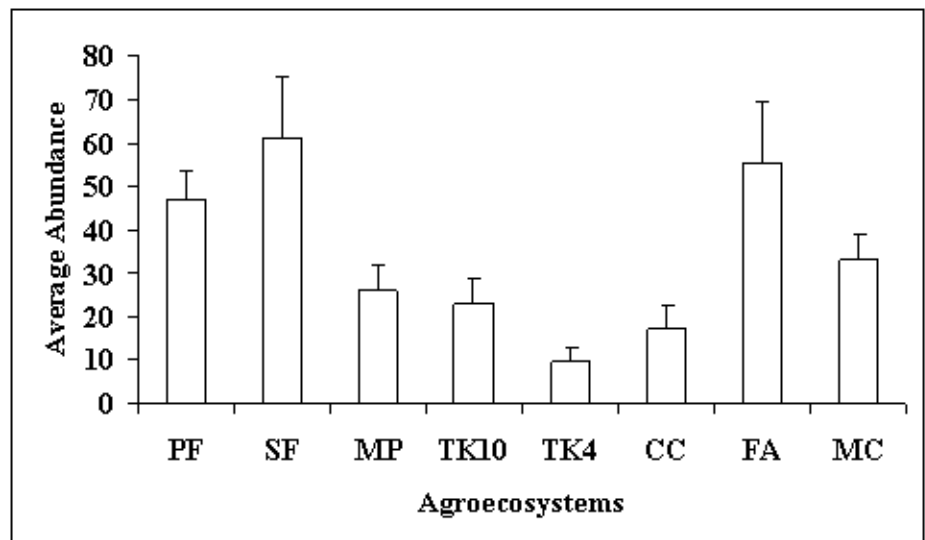

Fig. 1. Average abundance of beetles in agroecosystems, PF (primary forest), SF (secondary forest), MP (multispecies plantation), TK10 (10-year-old teak), TK4 (4-year-old teak), CC (cocoa plantation), FA (fallow). Means with the same letter are not significantly different at the $5 \%$ level. 


\subsection{Diversity and family richness}

The fallows were characterized by the highest diversity index followed by mixed-crop field. The 4-year-old teak plantations were distinct in having the lowest diversity index. Similar to beetle abundance, the variation of beetle diversity from one agroecosystem to another was highly significant $(p=0.001)$. Beetle diversity in fallows did not differ statistically from that of the secondary forests, but differed from that of the primary forests. The mixed-crop field beetle diversity did not differ significantly from those of the fallows and the secondary forests. Beetle diversity in the 4-year-old teak plantations differed from the other agroecosystems. Evenness indexes were nearly identical in all habitats (Fig. 2). Similarly, the fallows had the highest family richness observed followed by the secondary forests. We found a weak variation of the family richness observed between the secondary forests, primary forests, mixed-crop field and between the multi-species plantations, the cocoa plantations, and 10-year-old teak plantations (Fig. 3). The present results indicated that the combination of the two methods allowed us to collect more than $70 \%$ of the total families present in each agroecosystem.

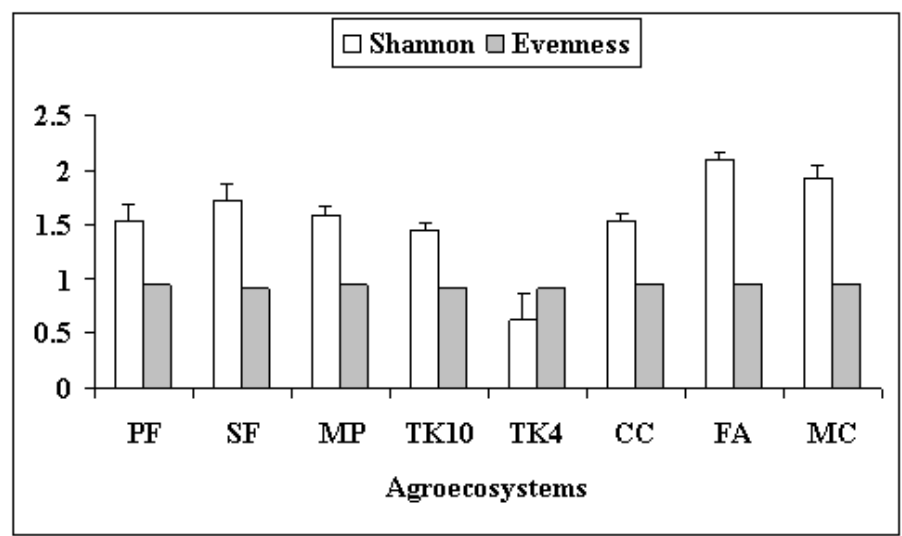

Fig. 2. Beetle diversity in agroecosystems estimated by the Shannon and evenness indices, PF (primary forest), SF (secondary forest), MP (multi-species plantation), TK10 (10-year-old teak), TK4 (4-year-old teak), CC (cocoa plantation), FA (fallow), MC (mixed-crop field). Means with the same letter are not significantly different at the $5 \%$ level.

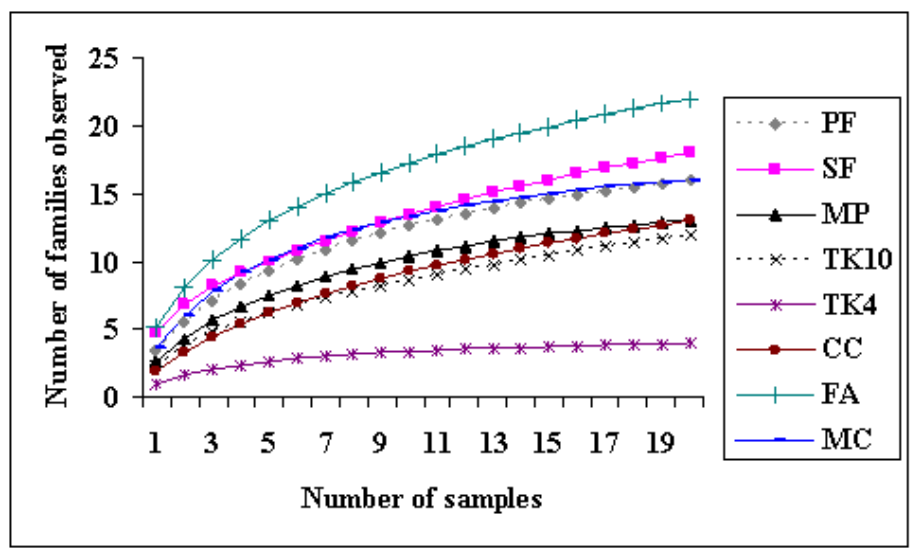

Fig. 3. Accumulation curves of families observed in the agroecosystems, $P F$ (primary forest), SF (secondary forest), MP (multi-species plantation), TK10 (10-year-old teak), TK4 (4-year-old teak), CC (cocoa plantation), FA (fallow), MC (mixed-crop field). 


\subsection{Similarity}

The Sorensen index of similarity allowed habitat grouping according to beetle composition (families). The dendrogram obtained indicated two groups of the agroecosystems. The first group was composed of the primary forest, 10year-old teak plantation and cocoa plantations.
Proportion of shared families in the first group of agroecosystems was about $75 \%$. The second group was composed of the secondary forest, mixed-crop field and fallow, and proportion of shared families was about $70 \%$. Multi-species plantations and 4-year-old teak plantations were different from each other and from the two groups (Fig. 4).

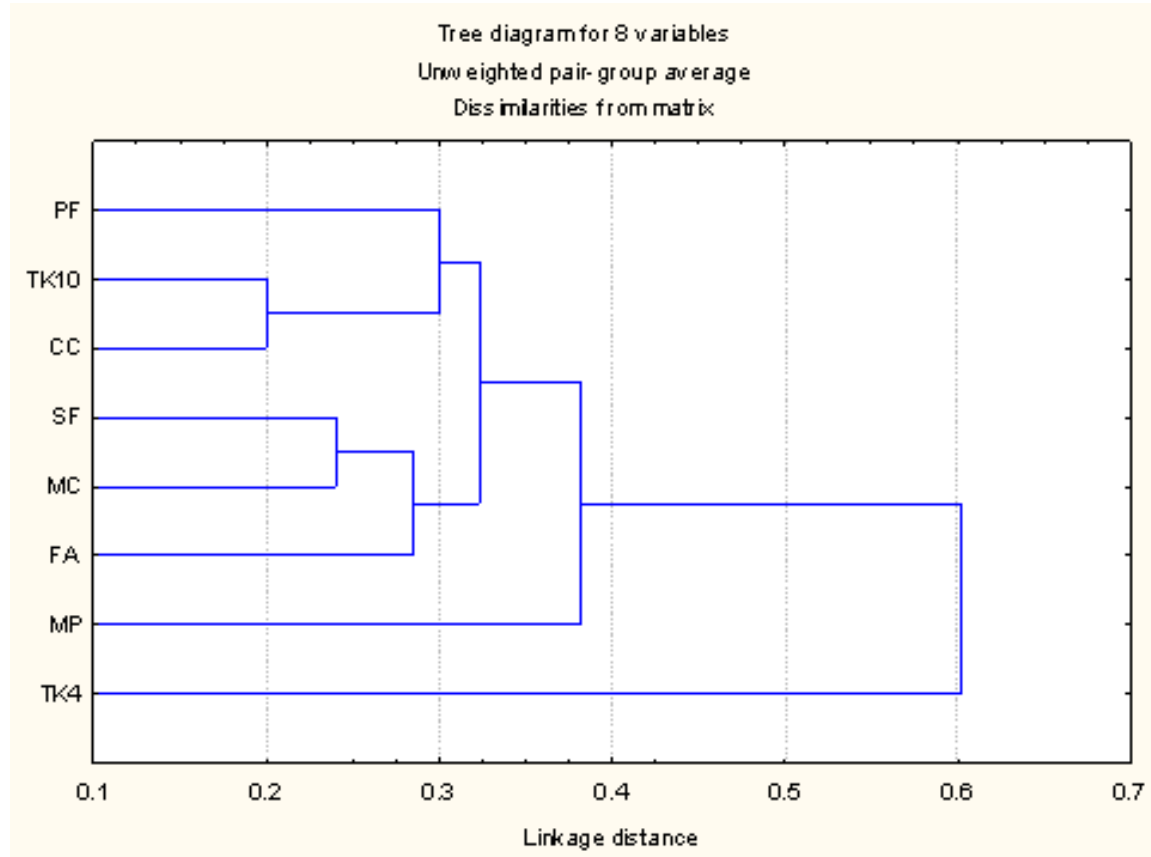

Fig. 4. Dendrogram showing groups of the agroecosystems according to the species composition, PF (primary forest), SF (secondary forest), MP (multi-species plantation), TK10 (10-year-old teak), TK4 (4-year-old teak), CC (cocoa plantation), FA (rural fallows), MC (mixed-crop field).

\section{Discussion}

The three most abundant families, Staphylinidae, Scydmaenidae, and Curculionidae, represented more than half of the total specimens collected. The common and rare beetle groups were represented by many families but fewer individuals. Many of the rare families were represented by only one individual and only in one agroecosystem. The number of individuals representing the abundant beetle group and the common beetle group did not vary statistically between habitats, contrary to that of the rare beetle group. Beetle abundance in the secondary forest differed from that of the teak plantations, the multi-species plantations, the cocoa plantations, and the mixed-crop fields. But, there was no statistical difference between the secondary forest, the primary forest, and the fallow. The explanation of these results is that the abundant beetles occurred mainly in the secondary forests. Secondary forests contained more than half of the total number of beetles sampled. The secondary forests were disturbed by the forest fires in the past but contained the greatest number of individuals sampled. The disturbances caused by forest fires enhanced the re-colonization of this habitat by arthropods after forest fires (Moretti et al., 2004). The fallows were transformed forests in which the vegetation was destroyed by agricultural activities and replaced by the secondary bush cover. The reconstitution of this habitat and its conversion to a more stable ecosystem would benefit its 
colonization by ground beetles. In the fallows, the abundance of beetles was lower than that of the secondary forests with diversity and family richness being relatively high. Studies conducted in Mexico (Lavelle \& Kohlmann, 1984), and in Ivory Coast (Gilot et al., 1995) revealed that density of soil microfauna in tropical forests was higher than in cultivated areas. The soil microfauna compared in this study to beetles was highly abundant in the forests particularly in secondary forest. Primary forests were less disturbed by human activities than the secondary forests and the fallows and they have more abundant beetle fauna. Contrary to soil microfauna, the beetle abundance and diversity were high in cultivated areas, particularly in mixedcrop field (Kra et al., 2008). However, the multispecies plantation, the monospecific plantations (the 4-year-old and 10-year-old teak plantations) and the cocoa plantations had the lowest beetle abundances and diversities. The transformation of natural habitats into monospecific and multispecies plantations, strongly disturbed the soil and the litter. This habitat modification resulted in the decline of the rare beetle families and their absence in the 4-year-old teak plantations. Soil management intervention can have dramatic effects on soil invertebrate communities (Beare et al., 1997; Fragoso et al., 1997; Giller et al., 1997; Barros et al., 2002, 2003; Decaëns et al., 2004). The 4-yearold teak, 10-year-old teak, multi-species plantations, and the cocoa plantations were characterized by low beetle abundance and diversity in spite of the abundance of leaf litter leaves and ground vegetation in cocoa and 10-year-old teak plantations. The similarity observed between some agroecosystems was based on the presence of the same beetle families in those habitats. The secondary forest, mixed-crop field and 10-year-old teak plantations had similar numbers of beetle families. It is the confirmation of results by the post-hoc grouping of beetle diversity for the two groups. We observed that many polyphagous species that favour disturbed habitats easily migrated to neighbouring habitats. The presence of tourist species and species transition between ecosystems depends on their mobility (Moreno \& Halffter, 2001).

However, the litter in cocoa plantations was constantly disturbed contrary to the 10-year-old teak plantations. The litter of cocoa plantations and 10year-old teak plantations was predominantly composed of the leaves of only one plant species and did not favour requirements for all the beetles.
Variation in the amounts of leaf litter, logs, rocks, and debris is likely to have the most profound effect on ground beetles, positively influencing their habitat (Lassau et al., 2005). Rossi and Blanchart (2005) obtained similar results in southern India. They showed that various soil management practices induce great changes in the composition of the soil fauna associated with certain agroecosystems, and that the density of the soil microfauna in monospecific acacia plantations was low compared to that of forests. The 4-yearold teak plantations are characterized by recent disturbances. The very poor vegetation cover has not been able to produce litter suitable for colonization by soil fauna. The organic resources of this habitat were less diversified. The low diversity of resources led to an impoverishment of specific diversity as was shown by the worms and termite faunas (Basu et al., 1996; Blanchart \& Julka, 1997). The beetle abundance and the diversity in these recently transformed ecosystems were very low compared to the older 10-year-old teak plantations. Abundance was low in regenerating forest and cocoa plantations, but it was relatively high in the mixed-crop fields (higher than in forests). It is interesting to note that the beetle richness in mixedcrop fields was similar to that of the primary forests but they differed in their diversity. The mixed-crop field and its diversity of cultivated plants produced a diversified litter that was favoured by beetles. In the mixed-crop field chosen, we can find banana trees, yam, pimento, brinjal and cocoa.

\section{Conclusion}

Beetle sampling using soil monolith extraction methods and the Ants of Leaf Litter protocol allowed us to estimate the distribution and the abundance of beetles in different agroecosystems imposed over the sampling grid. The disturbed ecosystems represented by the monospecific and multispecies plantations, the cocoa plantations apparently decrease beetle fauna diversity and abundance. Despite agricultural activities, beetle abundance and diversity were relatively high in the mixed-crop field. The less disturbed ecosystems, represented by forests and the fallows, were characterized by the highest beetle abundance. The abundant and common beetle groups were distributed throughout the sampling area, but the number of rare beetle groups was very low in disturbed ecosystems. 


\section{Acknowledgements}

We thank the many farmers in Oumé who provided access to their land for this study. We are also extremely grateful to Prof Tano, Prof Tondoh, Dr. Konaté, Dr. Tiho, and Dr. Yéo for their technical assistance. This work was conducted under the Conservation and Sustainable Management of Below-Ground Biodiversity (CSM-BGBD) project. We are much obliged to C. Majka, Nova Scotia Museum, Halifax, Nova Scotia, Canada, for reviewing the first draft of this manuscript and to P. Cheers (LFC) for editing it.

\section{References}

Agosti D. \& Alonso L.E., 2000. The ALL Protocol a standard protocol for the collection of grounddwelling ants. In: Agosti D., Mayer J.D., Alonso L.E. \& Schultz R., Eds ANTS: Standard methods for measuring and monitoring biodiversity. Smithsonian Institution Press, Washington, DC. pp.122-144

Barros E., Grimaldi M., Sarrazin M., Chauvel A., Mitja D., Desjardins T. \& Lavelle P., 2004. Soil physical degradation and changes in macrofaunal communities in Central Amazon. Appl. Soil Ecol. 26: 157-168.

Barros E., Neves A., Blanchart E., Fernandes E.C.M., Wandelli E., \& Lavelle P., 2003. Development of the soil macrofauna community under silvopastoral and agrosilvicultural systems in Amazonia. Pedobiologia 47: 273-280.

Barros E., Pashanasi B., Constantino R. \& Lavelle P., 2002. Effects of land-use system on the soil macrofauna in western Brazilian Amazonia. Biol. Fert. Soils 35: 338-347.

Basu P., Blanchart E. \& Lepage M., 1996. Termite (Isoptera) community in the Western Ghats, South India: influence of anthropogenic disturbance of natural vegetation. Eur. J. Soil Biol. 32: 113-121.

Beare M.H., Reddy M.V., Tian G. \& Srivastava S.C., 1997. Agricultural intensification, soil biodiversity and agroecosystem function in the tropics: the role of decomposer biota. Appl. Soil Ecol. 6: 87-108.
Blanchart E. \& Julka J.M., 1997. Influence of forest disturbance on earthworm (Oligochaeta) communities in the Western Ghats (South India). Soil Biol. Biochem. 29: 303-306.

Colwell R.K., 2005. EstimateS: Statistical estimate of species richness and shared species from samples. Version 7.5. Persistent URL purl.oclc.org/estimates.

Decaëns T., Jiménez J.J., Barros E., Chauvel A., Blanchart E., Fragoso C. \& Lavelle P., 2004. Soil macrofaunal communities in permanent pastures derived from tropical forest or savanna. Agr. Ecosyst. Environ. 103: 301-312.

Delvare G. \& Aberlenc H-P., 1989. Les insectes d'Afrique et d'Amérique tropicale. Clé pour la reconnaissance des familles. CIRAD, Montpellier, France, 302 pp.

Forsythe T.G., 1987. The relationship between body form and habit in some Carabidae (Coleoptera). J. Zool. Soc. London 211: 643-666.

Fragoso C., Brown G.G., Patrón J.C., Blanchart E., Lavelle P., Pashanasi B., Senapati B. \& Kumar T., 1997. Agricultural intensification, soil biodiversity and agroecosystem function in the tropics: the role of earthworms. Appl. Soil Ecol. 6: 17-35.

Giller K.E., Beare M.H., Lavelle P., Izac A-M.N. \& Swift M.J., 1997. Agricultural intensification, soil biodiversity and agroecosystem function. Appl. Soil Ecol. 6: 3-16.

Giller P.S., 1996. The diversity of soil communities, the 'poor man's tropical rainforest'. Biodivers. Conserv. 5: 135-168.

Gilot C., Lavelle P., Blanchart E., Keli J., Kouassi P., \& Guillaume G., 1995. Biological activity of soils in Hevea stands of different ages in Côte d'Ivoire. Acta Zool. Fenn. 196: 186-190.

Kra K.D., Klimaszewski, J., Doumbia, M., Aidara, D and Dagnogo, M., 2008. Comparing beetle abundance and diversity values along a land use gradient in tropical Africa (Oumé, Ivory Coast). Zool. Stud., 47 (4): 429-437).

Krebs C.J., 2002. Program for Ecological Methodology. Version 6.1. Benjamin Cummings, Vancouver, British Columbia, Canada.

Krell F.T., Mahiva, V.S., Kouakou, C., N'goran, P., 
Krell-Westervwalbesloh S., Newman D.H., WeiB I. \& Doumbia M., 2005. Human influence on the dung fauna in afrotropical grasslands (Insecta: Coleoptera). In: Huber B.A., Sinclair, B.J., Lampe, K-H (eds) Proceedings $5^{\text {th }}$ International Symposium Tropical Biology, Bonn, 2005.

Lawrence J.F., Hastings A.M., Dallwitz M.J., Paine T.A. \& Zurcher E.J., 1999. Beetles of the world. INTkEY version 5.09 , CSIRO Division of Entomology, Canberra, Australia.

Lassau S.A., Hochuli D.F., Cassis G., \& Reid C.A.M., 2005. Effects of habitat complexity on forest beetle diversity: do functional groups respond consistently? Divers. Distrib. 11 : 73-82.

Lavelle P. \& Kohlmann B., 1984. Étude quantitative de la macrofaune du sol dans une forêt tropicale humide du Mexique (Bonampak, Chiapas). Pedobiologia 27: 377-393.

Leraut P., 2003. Le guide entomologique. Delachaux et Nestlé, Paris, France, 527 pp.

Lövei G.L. \& Sunderland K.D., 1996. Ecology and behavior of ground beetles (Coleoptera: Carabidae). Annu. Rev. Entomol. 41: 231-256.

Magagula C.N., 2003. Changes in carabid beetle diversity within a fragmented agricultural landscape. Afr. J. Ecol. 41: 23-30.

Moreno C.E. \& Halffter G., 2001. Spatial and temporal analysis of $\alpha, \beta$ and $\gamma$ diversities of bats in a fragmented landscape. Biodivers. Conserv. 10: 367-382.

Moretti M., Obrist M.K. \& Duelli P., 2004. Arthropod biodiversity after forest fires: winners and losers in the winter fire regime of the southern Alps. Ecography 27: 173-186.

Rossi J-P. \& Blanchart E., 2005. Seasonal and land-use induced variations of soil macrofauna composition in the Western Ghats, southern India. Soil Biol. Biochem. 37: 1093-1104.

Setälä H., Laakso J., Mikola J. \& Huhta V., 1998. Functional diversity of decomposer organisms in relation to primary production. Appl. Soil Ecol. 9: 25-31.

Thomas D.B. Jr. 1983. Tenebrionid beetle diversity and habitat complexity in the eastern Mojave Desert USA. Coleopt. Bull. 37: 135-147.

Wall D.H. \& Moore J.C. 1999. Interactions underground-soil biodiversity, mutualism, and ecosystem processes. BioScience 49: 109-117. 